\title{
Preferences for mHealth Technology and Text Messaging Communication in Patients With Type 2 Diabetes: Qualitative Interview Study
}

Julie C Lauffenburger ${ }^{1}$, PharmD, PhD; Renee A Barlev ${ }^{1}$, MD, MPH; Ellen S Sears ${ }^{1}$, BS; Punam A Keller ${ }^{2}$, PhD; Marie E McDonnell ${ }^{1}$, MD; Elad Yom-Tov ${ }^{3}$, PhD; Constance P Fontanet ${ }^{1}$, MPH; Kaitlin Hanken ${ }^{1}$, MPH; Nancy Haff ${ }^{1}$, MD, MPH; Niteesh K Choudhry ${ }^{1}$, MD, PhD

\footnotetext{
${ }^{1}$ Brigham and Women's Hospital, Harvard Medical School, Boston, MA, United States

${ }^{2}$ Dartmouth College, Dartmouth, NH, United States

${ }^{3}$ Microsoft Research, Herzliya, Israel
}

\section{Corresponding Author:}

Julie C Lauffenburger, PharmD, PhD

Brigham and Women's Hospital, Harvard Medical School

1620 Tremont Street

Suite 3030

Boston, MA, 02120

United States

Phone: 16175258865

Email: jlauffenburger@bwh.harvard.edu

\begin{abstract}
Background: Individuals with diabetes need regular support to help them manage their diabetes on their own, ideally delivered via mechanisms that they already use, such as their mobile phones. One reason for the modest effectiveness of prior technology-based interventions may be that the patient perspective has been insufficiently incorporated.

Objective: This study aims to understand patients' preferences for mobile health (mHealth) technology and how that technology can be integrated into patients' routines, especially with regard to medication use.

Methods: We conducted semistructured qualitative individual interviews with patients with type 2 diabetes from an urban health care system to elicit and explore their perspectives on diabetes medication-taking behaviors, daily patterns of using mobile technology, use of mHealth technology for diabetes care, acceptability of text messages to support medication adherence, and preferred framing of information within text messages to support diabetes care. The interviews were digitally recorded and transcribed. The data were analyzed using codes developed by the study team to generate themes, with representative quotations selected as illustrations.

Results: We conducted interviews with 20 participants, of whom $12(60 \%)$ were female and $9(45 \%)$ were White; in addition, the participants' mean glycated hemoglobin $\mathrm{A}_{1 \mathrm{c}}$ control was 7.8 (SD 1.1). Overall, 5 key themes were identified: patients try to incorporate cues into their routines to help them with consistent medication taking; many patients leverage some form of technology as a cue to support adherence to medication taking and diabetes self-management behaviors; patients value simplicity and integration of technology solutions used for diabetes care, managing medications, and communicating with health care providers; some patients express reluctance to rely on mobile technology for these diabetes care behaviors; and patients believe they prefer positively framed communication, but communication preferences are highly individualized.

Conclusions: The participants expressed some hesitation about using mobile technology in supporting diabetes self-management but have largely incorporated it or are open to incorporating it as a cue to make medication taking more automatic and less burdensome. When using technology to support diabetes self-management, participants exhibited individualized preferences, but overall, they preferred simple and positively framed communication. mHealth interventions may be improved by focusing on integrating them easily into daily routines and increasing the customization of content.
\end{abstract}

(J Med Internet Res 2021;23(6):e25958) doi: 10.2196/25958 


\section{KEYWORDS}

diabetes; technology; mobile health; medication adherence; mobile phone

\section{Introduction}

\section{Background}

Achieving optimal glycemic control substantially decreases the risk of long-term complications in individuals with type 2 diabetes [1-3]. Yet, more than $40 \%$ of patients with diabetes do not achieve their glycemic targets [4]. Medication adherence is an important factor in achieving diabetes control and improving clinical outcomes [5-8]. On average, less than half of patients take their medications as prescribed [7,8]. Managing diabetes also requires simultaneous adherence to diet and physical activity goals and achieving weight loss [5,9-12]. Although health care professionals can recommend treatments and promote healthy behaviors, activities like medication adherence, weight monitoring, dietary choices, and exercise must be self-managed by the patients [13,14]. Accordingly, to meaningfully improve outcomes, individuals with diabetes need regular support and feedback to help them manage these behaviors on their own, ideally delivered via mechanisms that they already use.

As of 2019 , more than $80 \%$ of the US population owns smartphones, with relatively consistent uptake across most sociodemographic groups. Among the many functionalities of smartphones, text messaging is especially inexpensive and can provide reminders, education, and motivational support on an ongoing basis [15]. Growing evidence supports the effectiveness of text messaging-based approaches for diabetes self-management $[15,16]$, although the magnitude of benefit that most patients receive is relatively modest [16-18].

One reason for this limited effectiveness of text messaging-based interventions in patients with diabetes may be that patients' perspectives have been insufficiently incorporated into the message content and delivery. Little is known about specific preferences for mobile health (mHealth) technology for diabetes and how the technology could integrate into patients' routines, especially with regard to medication use [19-21]. Patients may also exhibit specific preferences for how they receive text messaging-based communication from health care professionals, which may affect patients' diabetes self-management activities.

\section{Objective}

Therefore, we conducted in-depth, semistructured qualitative interviews with individuals with type 2 diabetes to elicit and explore their perspectives on (1) the medication-taking behaviors and challenges in diabetes; (2) their daily patterns of using mobile technology; (3) their use of mHealth technology for diabetes care, medication management, and provider communication; (4) the acceptability of a text messaging-based system for supporting medication adherence; and (5) their preferred framing of information within text messages to support diabetes care.

\section{Methods}

\section{Study Participants and Recruitment}

Participants were eligible if they were 18 years or older, diagnosed with type 2 diabetes, and were taking 1 or more prescribed oral medication for that condition. It should be noted that participants who were also using insulin were not explicitly excluded to enhance generalizability. We recruited a purposive sample of participants for qualitative interviews through direct clinician referral from Mass General Brigham health centers (formerly Partners Health care) as well as posting in and recruiting from a web-based database of participants who expressed an interest in participating in research studies in and around Boston, Massachusetts [22]. The recruitment and interviews occurred between January and March 2020. Informed consent was obtained from all interview participants, and they received a US $\$ 30$ honorarium on the completion of the interview.

In this study, we followed the established standards for reporting qualitative research (ie, the COREQ [Consolidated Criteria for Reporting Qualitative Research] checklist) to ensure conformity with qualitative research standards, as recommended by the EQUATOR (Enhancing the Quality and Transparency of Health Research) Network [23,24]. Throughout the paper, we have referred to participants by their study ID to preserve anonymity. The Mass General Brigham Review Board approved this study.

\section{Qualitative Interviews}

To elicit deeply personal accounts and develop a greater understanding of participants' perceptions of diabetes management and the role of technology and text messaging-based solutions in their care, we chose to use semistructured, one-on-one qualitative interviews. To do so, the lead author, who had experience in qualitative methods, medication adherence, and clinical pharmacy, first drafted a comprehensive semistructured interview guide and circulated it for feedback and iterative refinement from other coinvestigators with expertise in qualitative methods, clinical medicine, mobile phone technology, diabetes, and medication adherence. Nonparticipant volunteers also pilot tested the guide, which led to no substantial changes. The guide covers separate but overlapping topics: (1) medication-taking behaviors and challenges in diabetes; (2) their use of mobile technology in their daily lives; (3) their use of technology for diabetes care, medication management, and provider communication; (4) general acceptability of a nonspecific text messaging-based system for medication management; and (5) preferred framing of information within text messages to support diabetes care (Multimedia Appendix 1, Table S1). The guide was used flexibly during the interviews to follow the natural flow of conversation and allow for free-flowing discussion by participants.

The participants were also shown 15 example text messages to respond to toward the end of the interview to further elicit perspectives on the framing of information. These text messages 
have been used in prior text messaging-based interventions for diabetes (Multimedia Appendix 1, Table S2) [25,26].

All interviews were conducted in English by a trained moderator who is also a practicing pharmacist (JCL). The interviews were conducted in person at secure locations around the Brigham and Women's Hospital. At the beginning of the interview, the participants completed a baseline questionnaire that included questions about self-reported adherence to medication [27,28] and patient activation [29,30] (Multimedia Appendix 1, Figure $\mathrm{S} 1$ ). Each interview lasted between 30 and 75 minutes (mean 38.5, SD 10.3), and a sequential identification number was assigned to each interview. We conducted interviews until saturation was reached; saturation of the data was reached by patient 19 and reaffirmed with patient 20 .

\section{Data Analyses}

The audio-recorded interviews were transcribed verbatim. Transcripts were checked for accuracy against the recordings. To conduct the data analysis, we used immersion-crystallization methods [31,32]. In brief, this approach involves immersing in the data and then crystalizing salient themes during this process. Three investigators independently annotated a selection of transcripts and devised preliminary topic codes, with major categories consisting of technology, health, medication, routine, and texting. Each transcript was analyzed by at least two reviewers. Preliminary coding revealed themes around (1) having cues in medication regimen, (2) preferences for simplicity in communication, (3) concern about the applicability of communication, (4) reluctance to rely on technology, and (5) preferences for positively framed texts. After discussion and review with the coinvestigators, the preliminary codes were revised and agreed upon. We also identified broad themes at this stage.

Dedoose software version 8.3.10 (SocioCultural Research Consultants, LLC) was used for storage, handling, and analysis of the data set. We continued the immersion-crystallization approach until all the data were examined. Several early themes were clear: the role of habits in medication management, tendencies to use technology for managing diabetes but also being reluctant to rely on it, the perceived need for technology to seamlessly integrate into routines to be useful, and preferences for positively framed health communication. After coding, all the transcripts were then reread to identify any additional themes.

\section{Results}

\section{Overview}

We conducted interviews with 20 participants, and their key baseline sociodemographic and clinical characteristics are shown in Table 1. Among the participants, 60\% (12/20) were female and $45 \%(9 / 20)$ were White; in addition, they had a mean glycated hemoglobin $\mathrm{A}_{1 \mathrm{c}}$ of 7.8 (SD 1.1). Although 65\% (13/20) of the participants reported missing at least one day of medication in the last 30 days, the overall rates of adherence were modestly high (ie, a mean of 1.15 days missed, SD 1.1) [27,28].

In the interviews, participants reflected in detail about their medication-taking behaviors and routines; how they integrate mobile technology in their daily lives; their experiences with using mHealth technology to manage their diabetes; and their preferred method of receipt and framing of health-related communication, especially with regard to their medications.

On the basis of these interviews, we identified 5 key themes related to medication taking, technology, and preferences, which are summarized in Textbox 1. We present each of these themes in more detail in the following sections, with representative quotations by participants from the transcripts shown in italics. We also share the specific reactions to potential text messages shown to the participants. 
Table 1. Participant characteristics.

\begin{tabular}{|c|c|c|c|c|c|c|c|}
\hline $\begin{array}{l}\text { Participant } \\
\text { ID }\end{array}$ & $\begin{array}{l}\text { Age } \\
\text { (years) }\end{array}$ & Gender & Race and ethnicity & Education level & $\begin{array}{l}\text { Medications in } \\
\text { regimen, } \mathrm{n}\end{array}$ & $\begin{array}{l}\text { Latest glycated } \\
\text { hemoglobin } \mathrm{A}_{1 \mathrm{c}} \\
\text { value }\end{array}$ & $\begin{array}{l}\text { Days that medica- } \\
\text { tions were missed in } \\
\text { the last } 30 \text { days, } n\end{array}$ \\
\hline $\mathrm{P} 1$ & 57 & Male & White & Some college & 15 & 7.2 & 1 \\
\hline $\mathrm{P} 2$ & 36 & Female & Black, Latino & Some college & 3 & 9.2 & 2 \\
\hline P3 & 42 & Female & White & Some college & 3 & 6.4 & 0 \\
\hline P4 & 68 & Male & White & College graduate & 6 & $-{ }^{a}$ & 1 \\
\hline P5 & 65 & Male & Black & Some college & 7 & $-^{\mathrm{a}}$ & 2 \\
\hline P6 & 54 & Female & Black & College graduate & 4 & 9.1 & 0 \\
\hline P7 & 56 & Male & White & Some college & 10 & 9.7 & 2 \\
\hline P8 & 56 & Female & Asian & Postgraduate & 14 & 6.4 & 2 \\
\hline P9 & 55 & Female & Black & College graduate & 2 & 7.3 & 0 \\
\hline $\mathrm{P} 10$ & 48 & Female & Black & Some college & 14 & 6.9 & 3 \\
\hline P11 & 45 & Female & White & College graduate & 4 & 6.8 & 0 \\
\hline $\mathrm{P} 12$ & 54 & Male & White & Postgraduate & 9 & 7.1 & 1 \\
\hline P13 & 78 & Male & White & College graduate & 8 & 9.3 & 1 \\
\hline P14 & 63 & Male & Black, native American & Postgraduate & 7 & 7.3 & 1 \\
\hline P15 & 71 & Male & White & Postgraduate & 8 & 8.6 & 1 \\
\hline P16 & 56 & Female & Black & Some college & 5 & 8.0 & 0 \\
\hline P17 & 59 & Female & Latino & Some college & 3 & 7.1 & 0 \\
\hline P18 & 21 & Female & Latino & Some college & 1 & 7.0 & 3 \\
\hline P19 & 58 & Female & Black & Some college & 14 & 6.9 & 0 \\
\hline $\mathrm{P} 20$ & 47 & Female & White & Postgraduate & 3 & 8.0 & 3 \\
\hline
\end{tabular}

${ }^{\mathrm{a} D a t a}$ not reported.

Textbox 1. Summary of key themes.

\section{Themes and key takeaways}

1. Patients try to incorporate cues into their routines to help them with consistent medication taking:

- Value of establishing a daily routine in supporting adherence

- Primarily use sight cues or habit cues

2. Many patients leverage some form of technology as a cue to support adherence to medication taking and diabetes self-management behaviors:

- Mobile phones serve as sight or habit cue for medication taking, either deliberately or accidentally

3. Value of simplicity and integration in technology solutions used for diabetes care, managing medications, and communicating with health care providers:

- Simplicity in communication and integration into routine can prevent exhaustion from being connected

- $\quad$ Straightforward, direct communication is preferred

4. Some patients express a reluctance to rely on mobile technology for these diabetes care behaviors:

- Concern about integration of mobile phones into daily lives for diabetes because of obsession with control values or concerns about screen time

5. Patients believe they prefer positively framed communication, but communication preferences are highly individualized:

- General preference for positively framed information

- Concerns about relevance of information to themselves or others, including advice and describing social support 


\section{Patients Try to Incorporate Cues Into Their Routines to Help Them With Consistent Medication Taking}

Participants described in great detail the value of a routine in supporting daily adherence to their diabetes medications, such as maintaining specific wake-up times, integrating medication taking into their bathroom use, or eating breakfast at the same time as their medications. Their medication-taking routines are most commonly supported by event-based cues centered on activities that are part of their normal routine, such as drinking coffee or using the bathroom or their mobile phone. These were sometimes supported by visual cues, such as sticky notes or a colorful pillbox in an obvious location. Others describe the act of glucose testing itself as supporting their medication taking and, therefore, the coupling of several activities that contribute to better blood sugar control. Conversely, for medications intended to be taken once a week, participants commonly described temporal cues, such as the day of the week:

If I remember church, I can remember to take the medication on Sundays. [P16]

I like little hacks; trying to remember little hacks like by the coffee pot or maybe in the restroom in the morning. Where you're brushing your teeth and you see your package of pills. [P4]

Even if my day is different-like I'm out all day today, so I'll probably have dinner before I go home, but as soon as I go home my pills are on my computer, which is one of the first things I do, so I take 'em right away. [P1]

My container is sitting right there [by the keys on the kitchen counter], so there's a good chance I'm gonna look at it before I walk out the door. That's the strategy. [P12]

It's automatic, almost. It's almost part of getting my first cup of coffee. I put my machine in, press it to get the coffee, and then while it's coming, I'll go over and test. [P15]

I'm programmed. I wake up. I make sure my coffee is brewing and then the pill before the coffee. That's like a religion for me. [P17]

Participants who largely reported a less automatic routine struggled with remembering to take their medications, filling their pillboxes, or recalling later whether they actually took their medications or not. Weekends appeared particularly difficult for participants because of the break in routine. Relatively few participants described behaviors that were fully automatic:

It's not that I don't remember the box. It's that I don't remember to fill certain medications in the box. [P8]

The weekend is the hardest because in the weekend, routines change a little. I'm not rushing. [P17]

Sometimes I forget, I get confused, and I don't remember that I have already taken it or not. If I take another one, then Ifeel worse because my sugar levels are really low. I think that's the hard part-to remember if I had it or not. [P18]
I'm usually doing other things while I'm trying to remember the medication and get the kids ready. "Did I take the medication? I don't remember.” Sometimes I didn't even realize I missed one. [P20]

\section{Many Patients Leverage Some Form of Technology as a Cue to Support Adherence to Medication Taking and Diabetes Self-management Behaviors}

For about half of the participants, their mobile phones served as cues for medication taking. In some cases, participants generated specific cues using their phones as reminders, such as alarms or calendar reminders. In other cases, participants described physically storing their medications near their phone during the day because they looked at their phones frequently and therefore used them as direct cues. Others recognized that using their phones or other technology would be difficult to support medication taking if they were not seamlessly integrated into their daily lives. Whether participants deliberately used their phones for medication taking appeared to depend in part on how strongly they felt they needed that as a cue or how strongly they felt most generally about their need for cues for medication taking:

The eight AM one I have missed. I usually have it in my pocket for the most part. The 12:00 one I don't miss 'cause it's usually in this pocket with the phone, and this phone comes in and out of my pocket all day long. [P1]

I always set two [alarms] to take medication; usually if I took it, I uncheck the other one so the alarm doesn't go off. If it does go off, that means I didn't take it. I have to do it, otherwise there's no way I'm gonna remember. [P2]

P8 explained why a phone may not always work by stating the following:

It's easier for men, because they have more pockets. I feel like I don't [notice it]; I have this cross-body thing [bag] that can hold my phone.

P12 explained why he uses his phone's calendar feature:

Because they remind me, and it's something I don't have to store in my head. It's just that some things are better left to a machine and automation.

P14 stated the following:

The cell phone could be a screwdriver, or a hammer. It's a tool. I don't have an emotional attachment to it. Now I'm gonna sound like a boomer. I got along without 'em. To me, it's just a tool, not the center of my life.

\section{Patients Value Simplicity and Integration for Technology Solutions Used for Diabetes Care, Managing Medications, and Communicating With Health Care Providers}

During the interview, participants reiterated that they disliked complicated technology or repetitive communication and offered several personal examples about likes and dislikes of communication that they currently receive. Simplicity was also 
valued because of its benefits in preventing exhaustion that comes from being constantly connected to technology and using technology for diabetes care. About one-third of the participants stated that they preferred written mobile communication rather than telephone calls, in part because of this desire for straightforwardness:

I just want you to get to the point and move on. Especially if you're gonna remind me to take my pills. I mean it's like did you take your pills today? You can either sit there and wait for a yes or a no. it's very simple. Simplicity; I like simplicity. [P1]

I love the little idea of-I love how straightforward the Brigham one [text] is. I love that. "Hey, did you take your meds? Respond back yes or no." I think that's great. Just straightforward. [P3]

I hate talking on the phone, so if I could have done that on my phone, like in an app or texting, would've been 1000 times-'cause I kept putting it off because I hate talking on the phone. Anything I don't have to do face to face and can actually text or something, way better. [P11]

Personally, Ifeel that watching out for what you have to eat and taking the pills and all this is frustrating in life. The longer the text message is the more like we're like, "Blah." We don't pay attention to it 'cause we don't want more stress. We don't want somebody telling, giving you all this lecture. [P17]

In another context, when specifically asked about whether they would use text messages for diabetes, the concept was largely received positively, as long as the information delivered was simple and considered actionable. Participants largely discussed managing their diabetes as something within their locus of control, or their own responsibility, and noted that text messages would have to adapt to that. Specific feedback on each example text message shown to the participants is displayed in Multimedia Appendix 1, Table S2:

I think that would be short, to the point at the time when you should be takin' it because texts, I think, are close to instantaneous to people. Most people have their phone in their pocket, especially the younger crowd. Older people, maybe not so much, but I think, even my generation is really into the phone, too. We mimic the younger kids because they do all the innovation and then show us how to do it. [P12]

The daily stuff, I think I have it pretty much under control. I don't think I need constant reminders, but I can see at some point it probably wouldn't hurt. [P7]

I like to text. I like to communicate. Communication is vital in my life and also with my own PCP [primary care physician], my own doctor, and all in your family and all. Yeah, so I like texts. [P17]

\section{Some Patients Express Reluctance to Rely on Mobile Technology for These Diabetes Care Behaviors}

Although participants largely reported high integration of mobile phones into their daily lives, they also expressed concern about this practice. In particular, they felt that technology could lead to an obsession with improving their diabetes numbers because of the rapid acquisition of those data. They described the physical exhaustion that comes from constantly concentrating on disease management, which may be amplified by technology use. There were also some stated concerns about overall screen time that led them to actively ignore or turn off some features that may be necessary to depend on mobile technology for diabetes care. Reluctance to rely on mobile technology may be associated with beliefs that technology is intrusive or patients are relinquishing control of their diabetes self-management:
You have to be your own advocate, but it's a full-time job for me to manage my healthcare around my doctors and my prescriptions and, you know, everything. It's just there are days where I just shut it off [the phone] and say, I can't today. I try to limit screen time anyways; my phone will be at the bottom of my bag, and it might go off, and I just won't hear it. [P8]
It's almost that I have a love hate relationship with the thing. I love it when I'm low. I hate it when I'm high. I tend to rely on my $A_{1 C}$ as my overall measure of how well I'm doing with my diabetes. [P12]
My phone is always on silent. I can't stand the noise. [P11]

\section{Patients Believe They Prefer Positively Framed Communication, but Communication Preferences Are Highly Individualized}

Participants expressed strong preferences for positively framed information within the communication they receive from health care providers. In their mind, positively framed communication involved motivational statements rather than penalizing statements or statements about the physical consequences of not taking medications. They also articulated similar desires for text messages to support medication use:
Because I'm into positive thinking in the way of trying to stay positive, trying to say things positive, so I like it when people send you those messages. [P5]
More of encouragement than, "You missed this. You didn't do this," more of the whole, "Let's get this done. Did you do"-more encouragement than penalized, feeling penalized. [P7]
Trying to find something positive, either a way to do something positive or a positive outcome of, "If you do this-” [P11]

Overall, participants wanted customized communication, and unless the information was applicable to them (eg, if they did not have family members involved in their care or social support), they surmised that they would likely ignore the text. Participants did not like texts that they deemed unrelated to their personal routine, such as texts with tips or advice. When 
asked about other types of communication preferences, such as whether to provide additional information beyond reminders, such as specific links to more information about diabetes self-care, or mentioning friends or family as sources of social support, participants had varied opinions about whether that would help them support medication taking:

People do things different ways. I was getting a text from somebody, I would wanna make it feel personal because then you tend not to ignore it than if it's a generic. [P9]

Friends and family's good, but friends and family a lotta times tend to be on the negative side of things and not as encouraging as you'd like, more, "You didn't do it, so you're bad." [P7]

To point out that friends or family could help me-but it's, like, "Well, they're not around." [P3]

I can't tell my family [about my diabetes] 'cause they're very judge-y. I can't stand when people micro-watch you. I don't feel comfortable telling by family because they'll be, like, "Well, can you eat that? Can you do that?" [P11]

It's pretty much known that if you eat well and exercise 30 minutes a day. I don't need to be reminded of that. [P6]

\section{Discussion}

\section{Principal Findings}

There is an urgent need to identify effective and sustainable strategies to engage individuals with type 2 diabetes on an ongoing basis and in their usual environments. mHealth technology has the potential to support self-care activities, only if its delivery of communication could be optimized [33]. In this qualitative interview study, participants expressed some hesitation about the role of mobile technology in supporting diabetes self-management but have largely incorporated or are open to incorporating it as a cue in the pursuit of making medication taking more automatic and less burdensome. When using technology to support diabetes self-management, participants generally preferred simple and positively framed communication.

\section{Comparison With Prior Work}

Of the few prior studies evaluating preferences for mHealth technology in diabetes, one conducted among 15 participants in the United Kingdom found a similar love-hate relationship with the increased awareness of glucose control provided by mHealth [34]. In another study of focus groups with 23 participants in the United Kingdom that concentrated on the acceptability of text messaging, participants relayed similar concerns about the relevance of content and expressed similar reluctance to rely on technology, largely because they felt that they should take personal responsibility for remembering to take medications [20]. Our study builds on this existing research but provides further insight into the role of mHealth in medication taking and preferences regarding message framing. Although preferences for simplicity have been observed in prior studies [35], it is notable that our US participants emphasized its importance in the context of reducing cognitive load and screen time [20,34,36,37].

Our findings also differ somewhat from other prior qualitative studies of text messaging, as our participants placed less emphasis on texts that invoke social concepts. A qualitative interview study in Argentina found that patients appreciated socially framed content in text messages [38], a finding consistent with survey data showing modestly high preferences for texts incorporating social support [21]. These differences could be attributable to culture or preferences for social support across different countries and populations, possibly because culture in the United States is generally more individualistic [39-42].

Related literature beyond text messaging programs about mobile apps reveals findings that are similar to ours. Patients have strong preferences for diabetes apps that are easy and efficient to use $[43,44]$, and strong integration in patients' daily routines has also been noted as desired features of mobile apps $[45,46]$. Similarly, communication preferences themselves have been thought to be highly individual [47]. However, several differences between mobile apps and text messaging programs should be noted: (1) participants must have a smartphone to use a mobile app, (2) participants must more actively open or engage with apps to derive benefits, and (3) participants express specific financial concerns about apps [44,46]. These considerations may be less relevant to mHealth messaging programs $[15,44]$.

\section{Implications of the Findings}

These findings offer several lessons for improving mHealth messaging programs for diabetes. Participants identified several strategies that are consistent with evidence from behavioral science, such as salience and framing of information [48-50]. For example, one key concept from the interviews was the desire for applicability and customization to ensure that the content is relevant and, therefore, salient to patients. Other limited existing evidence also suggests that mobile technology-based interventions may be most effective when information is tailored to the characteristics of individual patients, such as their specific barriers to adherence; of course, not all barriers can be easily addressed in text message solutions [51,52]. Furthermore, participants identified the importance of framing of communication, which is of demonstrated importance in other contexts, such as preventive health screenings and vaccinations $[48,49,53]$. These interviews suggested that framing, especially positively, may affect influence whether patients respond to text messaging programs in diabetes. Although, on average, patients prefer positive framing, persuasiveness of other framing may depend on patients' specific barriers, and framing in text messaging programs specifically may warrant further empirical exploration.

Other design factors also appear to be important for the success of text messaging-based interventions in diabetes. The simplicity and ease of incorporating a hypothetical text messaging-based system into patients' daily lives appear to be central to engendering the automaticity in medication taking that patients aim for. Mobile phones may already serve as habit-based cues, which could support patients until they no longer need to rely on those cues. However, there may be other 
ways in which text messaging programs should be better integrated into clinical care, such as more seamless communication with patient portals or electronic health record systems. Overall, technology can overcome many medication adherence barriers, including enhancing planning, being objective or not judgmental, and a ubiquitous presence, but more research is needed on the characteristics of patients who may benefit the most. Similarly, text messages for medication adherence could also be more persuasive than text messages for diet and exercise reminders because adherence behaviors are generally easier to implement; however, any differences are not yet well characterized.

\section{Limitations}

This study has several limitations. First, this study was conducted in an urban academic medical center in eastern Massachusetts and recruited directly from clinics or from a web-based database of interested subjects, which could have affected generalizability; however, we enrolled a clinically and demographically diverse sample of participants. Second, the mean age of the study sample was 54 years (SD 12.3), which reflects the age distributions of individuals with type 2 diabetes in the United States; nevertheless, the results could have underrepresented younger viewpoints, who may have differing perspectives on technology use [54]. Third, because we conducted the interviews in person, response bias may have been possible. Finally, although participants using insulin were not excluded, the results may not be generalizable to patients exclusively using injectables to manage their diabetes.

\section{Conclusions}

Participants appeared to express some trepidation about the daily role of mobile technology, but they have largely incorporated it or are open to incorporating it as a cue in the pursuit of making medication taking more automatic and less burdensome. mHealth interventions may be improved by focusing on easy integration into daily routines and increasing personalization. Careful, tailored application of behavioral science theories may be especially important in a society that increasingly relies on at-home, virtual care for managing diabetes.

\section{Acknowledgments}

This research was supported by a grant from the National Institutes of Health National Institute on Aging to Brigham and Women's Hospital (NKC is Center PI: P30AG064199). JCL was also supported in part by a career development grant (K01HL141538) from the National Institutes of Health.

\section{Conflicts of Interest}

RAB is funded by an unrestricted educational grant from Boehringer Ingelheim to the Brigham and Women's Hospital. NKC has received research grants from Boehringer Ingelheim and Humana payable to Brigham and Women's Hospital and receives consulting fees and holds equity in RxAnte.

\section{Multimedia Appendix 1}

Supplementary tables and figure.

[DOCX File, 177 KB-Multimedia Appendix 1]

\section{References}

1. Huang ES, Liu JY, Moffet HH, John PM, Karter AJ. Glycemic control, complications, and death in older diabetic patients: the diabetes and aging study. Diabetes Care 2011 Jun 19;34(6):1329-1336 [FREE Full text] [doi: 10.2337/dc10-2377] [Medline: 21505211]

2. Inzucchi SE, Bergenstal RM, Buse JB, Diamant M, Ferrannini E, Nauck M, et al. Management of hyperglycaemia in type 2 diabetes: a patient-centered approach. Position statement of the American Diabetes Association (ADA) and the European Association for the Study of Diabetes (EASD). Diabetologia 2012 Jun 20;55(6):1577-1596. [doi: 10.1007/s00125-012-2534-0] [Medline: 22526604]

3. Lau DC, Teoh H. Impact of current and emerging glucose-lowering drugs on body weight in type 2 diabetes. Can J Diabetes 2015 Dec;39 Suppl 5:148-154. [doi: 10.1016/j.jcjd.2015.09.090] [Medline: 26654858]

4. American Diabetes Association. 8. Pharmacologic approaches to glycemic treatment: standards of medical care in diabetes-2018. Diabetes Care 2017 Dec 08;41(Supplement 1):73-85. [doi: 10.2337/dc18-s008]

5. Carls GS, Tuttle E, Tan R, Huynh J, Yee J, Edelman SV, et al. Understanding the gap between efficacy in randomized controlled trials and effectiveness in real-world use of GLP-1 RA and DPP-4 therapies in patients with type 2 diabetes. Diabetes Care 2017 Nov 11;40(11):1469-1478. [doi: 10.2337/dc16-2725] [Medline: 28801475]

6. Fernández A, Quan J, Moffet H, Parker MM, Schillinger D, Karter AJ. Adherence to newly prescribed diabetes medications among insured Latino and White patients with diabetes. JAMA Intern Med 2017 Mar 01;177(3):371-379 [FREE Full text] [doi: 10.1001/jamainternmed.2016.8653] [Medline: 28114642]

7. Lin L, Sun Y, Heng BH, Chew DE, Chong P. Medication adherence and glycemic control among newly diagnosed diabetes patients. BMJ Open Diabetes Res Care 2017 Jul 31;5(1):e000429 [FREE Full text] [doi: 10.1136/bmjdrc-2017-000429] [Medline: 28878942] 
8. Capoccia K, Odegard PS, Letassy N. Medication adherence with diabetes medication: a systematic review of the literature. Diabetes Educ 2016 Feb 04;42(1):34-71. [doi: 10.1177/0145721715619038] [Medline: 26637240]

9. Lauffenburger JC, Lewey J, Jan S, Lee J, Ghazinouri R, Choudhry NK. Association of potentially modifiable diabetes care factors with glycemic control in patients with insulin-treated type 2 diabetes. JAMA Netw Open 2020 Jan 03;3(1):e1919645 [FREE Full text] [doi: 10.1001/jamanetworkopen.2019.19645] [Medline: 31968115]

10. Lauffenburger JC, Mahesri M, Choudhry NK. Not there yet: using data-driven methods to predict who becomes costly among low-cost patients with type 2 diabetes. BMC Endocr Disord 2020 Aug 17;20(1):125 [FREE Full text] [doi: 10.1186/s12902-020-00609-1] [Medline: $\underline{\text { 32807156] }}$

11. Gatwood JD, Chisholm-Burns M, Davis R, Thomas F, Potukuchi P, Hung A, et al. Disparities in initial oral antidiabetic medication adherence among veterans with incident diabetes. J Manag Care Spec Pharm 2018 Apr;24(4):379-389. [doi: 10.18553/jmcp.2018.24.4.379] [Medline: 29578849]

12. Mayberry LS, Osborn CY. Family support, medication adherence, and glycemic control among adults with type 2 diabetes. Diabetes Care 2012 Jun 26;35(6):1239-1245 [FREE Full text] [doi: 10.2337/dc11-2103] [Medline: 22538012]

13. Powers MA, Bardsley J, Cypress M, Duker P, Funnell MM, Fischl AH, et al. Diabetes self-management education and support in type 2 diabetes. Diabetes Educ 2017 Feb 24;43(1):40-53. [doi: 10.1177/0145721716689694] [Medline: 28118121]

14. Nadolsky KZ. Re: Consensus statement by the American Association of Clinical Endocrinologists and American College of Endocrinology on the comprehensive type 2 diabetes management algorithm - 2018 executive summary. Endocr Pract 2018 May;24(5):498. [doi: 10.4158/ep-2018-0062]

15. Lauffenburger JC, Choudhry NK. Text messaging and patient engagement in an increasingly mobile world. Circulation 2016 Jan 14;133:555-556. [doi: 10.1161/circulationaha.116.021182]

16. Thakkar J, Kurup R, Laba T, Santo K, Thiagalingam A, Rodgers A, et al. Mobile telephone text messaging for medication adherence in chronic disease: a meta-analysis. JAMA Intern Med 2016 Mar 01;176(3):340-349. [doi:

10.1001/jamainternmed.2015.7667] [Medline: 26831740]

17. Dobson R, Whittaker R, Dale LP, Maddison R. The effectiveness of text message-based self-management interventions for poorly-controlled diabetes: a systematic review. Digit Health 2017 Nov 09;3:2055207617740315 [FREE Full text] [doi: 10.1177/2055207617740315] [Medline: 29942620]

18. Sahin C, Courtney KL, Naylor P, E Rhodes R. Tailored mobile text messaging interventions targeting type 2 diabetes self-management: a systematic review and a meta-analysis. Digit Health 2019 Apr 22;5:2055207619845279 [FREE Full text] [doi: 10.1177/2055207619845279] [Medline: 31041110 ]

19. Long H, Bartlett YK, Farmer AJ, French DP. Identifying brief message content for interventions delivered via mobile devices to improve medication adherence in people with type 2 diabetes mellitus: a rapid systematic review. J Med Internet Res 2019 Jan 09;21(1):e10421 [FREE Full text] [doi: 10.2196/10421] [Medline: 30626562]

20. Bartlett YK, Newhouse N, Long HA, Farmer A, French D. What do people with type 2 diabetes want from a brief messaging system to support medication adherence? Patient Prefer Adherence 2019 Sep; Volume 13:1629-1640. [doi: 10.2147/ppa.s217843]

21. Bartlett YK, Farmer A, Rea R, French DP. Use of brief messages based on behavior change techniques to encourage medication adherence in people with type 2 diabetes: developmental studies. J Med Internet Res 2020 May 13;22(5):e15989 [FREE Full text] [doi: 10.2196/15989] [Medline: 32401214]

22. Rally with Mass General Brigham. Mass General Brigham. URL: https://rally.partners.org/ [accessed 2021-01-22]

23. Tong A, Sainsbury P, Craig J. Consolidated criteria for reporting qualitative research (COREQ): a 32-item checklist for interviews and focus groups. Int J Qual Health Care 2007 Dec 16;19(6):349-357. [doi: 10.1093/intqhc/mzm042] [Medline: 17872937]

24. O’Brien BC, Harris IB, Beckman TJ, Reed DA, Cook DA. Standards for reporting qualitative research. Acad Med 2014;89(9):1245-1251. [doi: 10.1097/acm.0000000000000388]

25. Lauffenburger JC, Lewey J, Jan S, Makanji S, Ferro CA, Krumme AA, et al. Effectiveness of targeted insulin-adherence interventions for glycemic control using predictive analytics among patients with type 2 diabetes: a randomized clinical trial. JAMA Netw Open 2019 Mar 01;2(3):e190657 [FREE Full text] [doi: 10.1001/jamanetworkopen.2019.0657] [Medline: 30874782]

26. Choudhry NK, Isaac T, Lauffenburger JC, Gopalakrishnan C, Lee M, Vachon A, et al. Effect of a remotely delivered tailored multicomponent approach to enhance medication taking for patients with hyperlipidemia, hypertension, and diabetes: the STIC2IT cluster randomized clinical trial. JAMA Intern Med 2018 Sep 01;178(9):1182-1189 [FREE Full text] [doi: 10.1001/jamainternmed.2018.3189] [Medline: 30083727]

27. Wilson IB, Lee Y, Michaud J, Fowler FJ, Rogers WH. Validation of a new three-item self-report measure for medication adherence. AIDS Behav 2016 Nov 20;20(11):2700-2708 [FREE Full text] [doi: 10.1007/s10461-016-1406-x] [Medline: 27098408]

28. Lauffenburger JC, Fontanet CP, Isaac T, Gopalakrishnan C, Sequist TD, Gagne JJ, et al. Comparison of a new 3-item self-reported measure of adherence to medication with pharmacy claims data in patients with cardiometabolic disease. Am Heart J 2020 Oct;228:36-43. [doi: 10.1016/j.ahj.2020.06.012] [Medline: 32768690] 
29. Wolf MS, Smith SG, Pandit AU, Condon DM, Curtis LM, Griffith J, et al. Development and validation of the consumer health activation index. Med Decis Making 2018 Feb 13;38(3):334-343. [doi: 10.1177/0272989x17753392]

30. Gardner B, Abraham C, Lally P, de Bruijn G. Towards parsimony in habit measurement: testing the convergent and predictive validity of an automaticity subscale of the Self-Report Habit Index. Int J Behav Nutr Phys Act 2012 Aug 30;9(1):102 [FREE Full text] [doi: 10.1186/1479-5868-9-102] [Medline: 22935297]

31. Reis S, Biderman A, Mitki R, Borkan JM. Secrets in primary care: a qualitative exploration and conceptual model. J Gen Intern Med 2007 Sep 9;22(9):1246-1253 [FREE Full text] [doi: 10.1007/s11606-007-0186-4] [Medline: 17487521]

32. Borkan JM. Immersion/Crystallization. In: Crabtree BF, Miller WL, editors. Doing Qualitative Research. Thousand Oaks, California, United States: SAGE Publications; 1999:1-424.

33. Smith A. U.S. smartphone use in 2015. Pew Research Center. 2015. URL: http://www.pewinternet.org/2015/04/01/ us-smartphone-use-in-2015/ [accessed 2021-05-15]

34. Kelly L, Jenkinson C, Morley D. Experiences of using web-based and mobile technologies to support self-management of type 2 diabetes: qualitative study. JMIR Diabetes 2018 May 11;3(2):e9 [FREE Full text] [doi: 10.2196/diabetes.9743] [Medline: 30291098 ]

35. Feldman J. The simplicity principle in perception and cognition. Wiley Interdiscip Rev Cogn Sci 2016 Sep 29;7(5):330-340 [FREE Full text] [doi: 10.1002/wcs.1406] [Medline: 27470193]

36. Baxter S, Enderby P, Evans P, Judge S. Barriers and facilitators to the use of high-technology augmentative and alternative communication devices: a systematic review and qualitative synthesis. Int J Lang Commun Disord 2012;47(2):115-129. [doi: 10.1111/j.1460-6984.2011.00090.x] [Medline: 22369053]

37. Ranney ML, Choo EK, Cunningham RM, Spirito A, Thorsen M, Mello MJ, et al. Acceptability, language, and structure of text message-based behavioral interventions for high-risk adolescent females: a qualitative study. J Adolesc Health 2014 Jul;55(1):33-40 [FREE Full text] [doi: 10.1016/j.jadohealth.2013.12.017] [Medline: 24559973]

38. Moyano D, Morelli D, Santero M, Belizan M, Irazola V, Beratarrechea A. Perceptions and acceptability of text messaging for diabetes care in primary care in Argentina: exploratory study. JMIR Diabetes 2019 Mar 18;4(1):e10350 [FREE Full text] [doi: 10.2196/10350] [Medline: 30882362]

39. Bélanger E, Ahmed T, Vafaei A, Curcio CL, Phillips SP, Zunzunegui MV. Sources of social support associated with health and quality of life: a cross-sectional study among Canadian and Latin American older adults. BMJ Open 2016 Jun 28;6(6):e011503 [FREE Full text] [doi: 10.1136/bmjopen-2016-011503] [Medline: 27354077]

40. Litwin H. Social networks and well-being: a comparison of older people in Mediterranean and non-Mediterranean countries. J Gerontol B Psychol Sci Soc Sci 2010 Sep 14;65(5):599-608 [FREE Full text] [doi: 10.1093/geronb/gbp104] [Medline: 20008485]

41. Lawley KA, Willett ZZ, Scollon CN, Lehman BJ. Did you really need to ask? Cultural variation in emotional responses to providing solicited social support. PLoS One 2019 Jul 12;14(7):e0219478 [FREE Full text] [doi:

10.1371/journal.pone.0219478] [Medline: 31299054]

42. Oyserman D, Coon HM, Kemmelmeier M. Rethinking individualism and collectivism: evaluation of theoretical assumptions and meta-analyses. Psychol Bull 2002;128(1):3-72. [doi: 10.1037/0033-2909.128.1.3]

43. Torbjørnsen A, Ribu L, Rønnevig M, Grøttland A, Helseth S. Users' acceptability of a mobile application for persons with type 2 diabetes: a qualitative study. BMC Health Serv Res 2019 Sep 06;19(1):641 [FREE Full text] [doi:

10.1186/s12913-019-4486-2] [Medline: 31492176]

44. Peng W, Kanthawala S, Yuan S, Hussain SA. A qualitative study of user perceptions of mobile health apps. BMC Public Health 2016 Nov 14;16(1):1158 [FREE Full text] [doi: 10.1186/s12889-016-3808-0] [Medline: 27842533]

45. Rossmann C, Riesmeyer C, Brew-Sam N, Karnowski V, Joeckel S, Chib A, et al. Appropriation of mobile health for diabetes self-management: lessons from two qualitative studies. JMIR Diabetes 2019 Mar 29;4(1):e10271 [FREE Full text] [doi: 10.2196/10271] [Medline: $\underline{30924786}$ ]

46. Scheibe M, Reichelt J, Bellmann M, Kirch W. Acceptance factors of mobile apps for diabetes by patients aged 50 or older: a qualitative study. Med 20 2015 Mar 02;4(1):e1 [FREE Full text] [doi: 10.2196/med20.3912] [Medline: 25733033]

47. Baptista S, Wadley G, Bird D, Oldenburg B, Speight J, My Diabetes Coach Research Group. User experiences with a type 2 diabetes coaching app: qualitative study. JMIR Diabetes 2020 Jul 17;5(3):e16692 [FREE Full text] [doi: 10.2196/16692] [Medline: 32706649]

48. Keller PA, Lipkus IM, Rimer BK. Affect, framing, and persuasion. J Mark Res 2018 Oct 10;40(1):54-64. [doi: 10.1509/jmkr.40.1.54.19133]

49. Purnell JQ, Thompson T, Kreuter MW, McBride TD. Behavioral economics: "nudging" underserved populations to be screened for cancer. Prev Chronic Dis 2015 Jan 15;12:E06 [FREE Full text] [doi: 10.5888/pcd12.140346] [Medline: 25590600]

50. Gong J, Zhang Y, Yang Z, Huang Y, Feng J, Zhang W. The framing effect in medical decision-making: a review of the literature. Psychol Health Med 2013 Dec;18(6):645-653. [doi: 10.1080/13548506.2013.766352] [Medline: 23387993]

51. Piette JD, Farris KB, Newman S, An L, Sussman J, Singh S. The potential impact of intelligent systems for mobile health self-management support: Monte Carlo simulations of text message support for medication adherence. Ann Behav Med 2015 Feb 1;49(1):84-94 [FREE Full text] [doi: 10.1007/s12160-014-9634-7] [Medline: 25082177] 
52. Hartz J, Yingling L, Powell-Wiley TM. Use of mobile health technology in the prevention and management of diabetes mellitus. Curr Cardiol Rep 2016 Dec 8;18(12):130. [doi: 10.1007/s11886-016-0796-8] [Medline: 27826901]

53. Levin IP, Schneider SL, Gaeth GJ. All frames are not created equal: a typology and critical analysis of framing effects. Organ Behav Hum Decis Process 1998 Nov;76(2):149-188. [doi: 10.1006/obhd.1998.2804] [Medline: 9831520]

54. Bullard KM, Cowie CC, Lessem SE, Saydah SH, Menke A, Geiss LS, et al. Prevalence of diagnosed diabetes in adults by diabetes type - United States, 2016. MMWR Morb Mortal Wkly Rep 2018 Mar 30;67(12):359-361 [FREE Full text] [doi: 10.15585/mmwr.mm6712a2] [Medline: 29596402]

\title{
Abbreviations \\ COREQ: Consolidated Criteria for Reporting Qualitative Research \\ EQUATOR: Enhancing the Quality and Transparency of Health Research \\ mHealth: mobile health
}

\author{
Edited by $R$ Kukafka; submitted 22.11.20; peer-reviewed by M Pikkemaat, X Liao; comments to author 23.12.20; revised version \\ received 19.01.21; accepted 30.04.21; published 11.06.21 \\ Please cite as: \\ Lauffenburger JC, Barlev RA, Sears ES, Keller PA, McDonnell ME, Yom-Tov E, Fontanet CP, Hanken K, Haff N, Choudhry NK \\ Preferences for mHealth Technology and Text Messaging Communication in Patients With Type 2 Diabetes: Qualitative Interview \\ Study \\ J Med Internet Res 2021;23(6):e25958 \\ URL: https://www.jmir.org/2021/6/e25958 \\ doi: $10.2196 / 25958$ \\ PMID:
}

CJulie C Lauffenburger, Renee A Barlev, Ellen S Sears, Punam A Keller, Marie E McDonnell, Elad Yom-Tov, Constance P Fontanet, Kaitlin Hanken, Nancy Haff, Niteesh K Choudhry. Originally published in the Journal of Medical Internet Research (https://www.jmir.org), 11.06.2021. This is an open-access article distributed under the terms of the Creative Commons Attribution License (https://creativecommons.org/licenses/by/4.0/), which permits unrestricted use, distribution, and reproduction in any medium, provided the original work, first published in the Journal of Medical Internet Research, is properly cited. The complete bibliographic information, a link to the original publication on https://www.jmir.org/, as well as this copyright and license information must be included. 